\title{
Equivalent modelling of wind and pv plants for harmonic studies in power electronics rich transmission networks
}

DOI:

10.1049/cp.2018.1773

\section{Document Version}

Accepted author manuscript

Link to publication record in Manchester Research Explorer

\section{Citation for published version (APA):}

Zhao, Y., Becirovic, E., \& Milanovic, J. V. (2018). Equivalent modelling of wind and pv plants for harmonic studies in power electronics rich transmission networks. In 11th IET International Conference on Advances in Power System Control, Operation and Management (APSCOM 2018) https://doi.org/10.1049/cp.2018.1773

\section{Published in:}

11th IET International Conference on Advances in Power System Control, Operation and Management (APSCOM 2018)

\section{Citing this paper}

Please note that where the full-text provided on Manchester Research Explorer is the Author Accepted Manuscript or Proof version this may differ from the final Published version. If citing, it is advised that you check and use the publisher's definitive version.

\section{General rights}

Copyright and moral rights for the publications made accessible in the Research Explorer are retained by the authors and/or other copyright owners and it is a condition of accessing publications that users recognise and abide by the legal requirements associated with these rights.

\section{Takedown policy}

If you believe that this document breaches copyright please refer to the University of Manchester's Takedown Procedures [http://man.ac.uk/04Y6Bo] or contact uml.scholarlycommunications@manchester.ac.uk providing relevant details, so we can investigate your claim.

\section{OPEN ACCESS}




\title{
Equivalent Modelling of Wind and PV Plants for Harmonic Studies in Power Electronics Rich Transmission Networks
}

\author{
Yuqi Zhao ${ }^{1}$ Elvisa Bećirović ${ }^{2}$ Jovica V. Milanović ${ }^{3}$ \\ ${ }^{1}$ Department of Electrical and Electronic Engineering, The University of Manchester, UK \\ E-mail: yuqi.zhao.uom@gmail.com \\ ${ }^{2}$ Department of Electrical and Electronic Engineering, The University of Manchester, UK \\ E-mail: elvisa.becirovic@manchester.ac.uk \\ ${ }^{3}$ Department of Electrical and Electronic Engineering, The University of Manchester, UK \\ E-mail: jovica.milanovic@manchester.ac.uk
}

\begin{abstract}
This paper investigates the effect of modelling of different aspects of renewable energy sources (RES) namely wind farms (WF) and photovoltaics (PV) plants as a first step towards development of the equivalent harmonic model of RES plant for harmonic propagation and mitigation studies in large transmission networks. The paper proposes a set of scaling factors that can be used when modelling the whole RES plant as a single harmonic source, considering different weather conditions, configurations, and harmonic cancellation effects of RES plants. The results facilitate the assessment of global contribution of power electronics connected RES to harmonic levels in transmission networks and more generally harmonic propagation studies in large power electronics reach transmission networks.
\end{abstract}

Keywords-Harmonics, renewable energy source, power electronics, uncertainty, Monte Carlo simulations

\section{INTRODUCTION}

Power quality (PQ) disturbances result in significant financial losses to both network operators and end users. With the rapid development of technology, there has been a great proliferation of power electronics (PE) devices into power systems including $\mathrm{PE}$ interface connected generation and load, FACTS devices and HVDC lines. As a consequence, there have been concerns about potential increase of harmonics in the system, which could lead to equipment overheating, insulation stress and load disruption, thus leading to significant financial losses. Considering that installed capacity of renewable energy sources connected to the system through PE interface is significant and constantly increasing the study of the influence of PE connected generation on harmonic levels in the system is highly needed.

In recent years, in order to reduce the thermal and maloperation damage caused by harmonic distortion, some mitigation methods such as line rectors, phasing shift transformers passive power filters (PPF) and active power filters (APF) have been widely used [1]. However, even though PPF are cheaper and more flexible, the resonance problem arises when large capacitive or inductive switching devices are connected to the network. Similarly, the complexity of system topologies limits the compensation ability of APF. Therefore, it is important to do more research based on different renewable systems models to optimise harmonic mitigation technologies.

This paper is one of the first, if not the first to model an independent renewable power plant (WF and PV plant) for harmonic propagation studies. Additionally, considering stochastic and intermittent nature of operation of RES and uncertainties associated with system operation and load, probabilistic harmonic modelling and analysis are adopted as more suitable than conventional deterministic approach in the study [2].

The $95^{\text {th }}$ percentile of total harmonic distortion (THD) calculated at the point of connection of RES plant is used as an index in the study to analyse different aspects of plant modelling. All models are developed and simulations performed using DigSILENT/PowerFactory $15.2[3]$.

\section{Methodology}

\section{WF and $P V$ plant configurations}

In the modelling of a WF, the wind power plant consists of a point of common coupling (PCC) bus connected to the external power grid, a collector bus connected to a total of 48 wind generators and two types of connection transformers that change voltage level. The voltage level of the plant is $0.69 / 33 / 138 \mathrm{KV}$. As the most commonly used connection configurations of wind turbines in the WF, parallel, star and T configuration [4,5], shown Fig.1 Fig.2 and Fig.3, respectively are considered in the study. All three topologies consist of identical 48 wind generators.

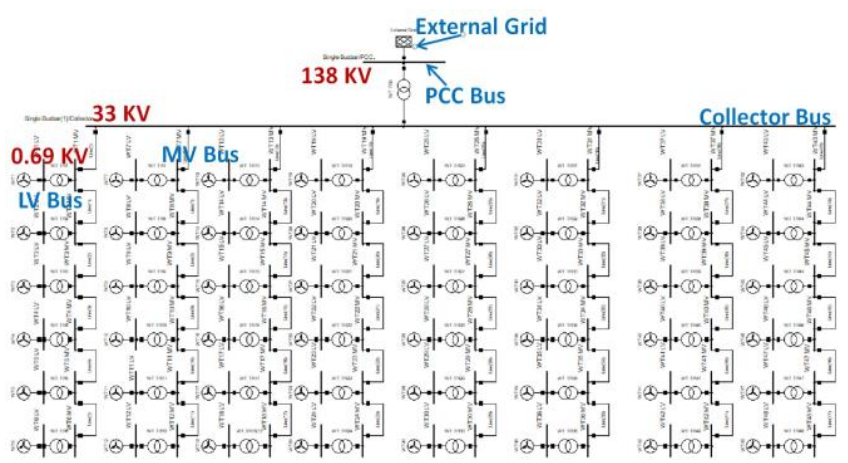

Fig. 1: WF with parallel configuration

The PV plant consists of a PCC bus connected to an external power grid, a collector bus connected a total of 48 PV subsections and two types of transformers that change voltage level. Each substation consists of 4 array channels. The voltage level of the PV plant is $0.4 / 10 / 138 \mathrm{KV}$. The configuration of parallel PV plant is shown as Fig.4. 


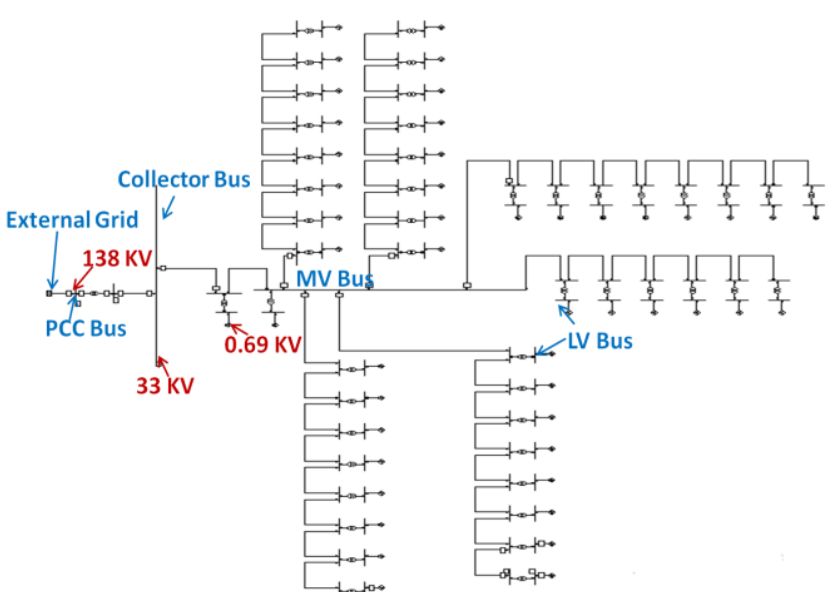

Fig. 2: WF with star configuration

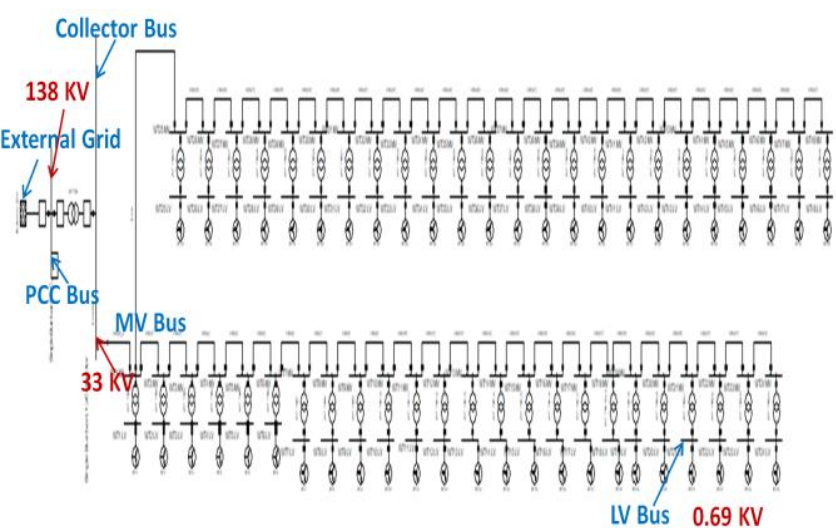

Fig. 3: WF with T configuration

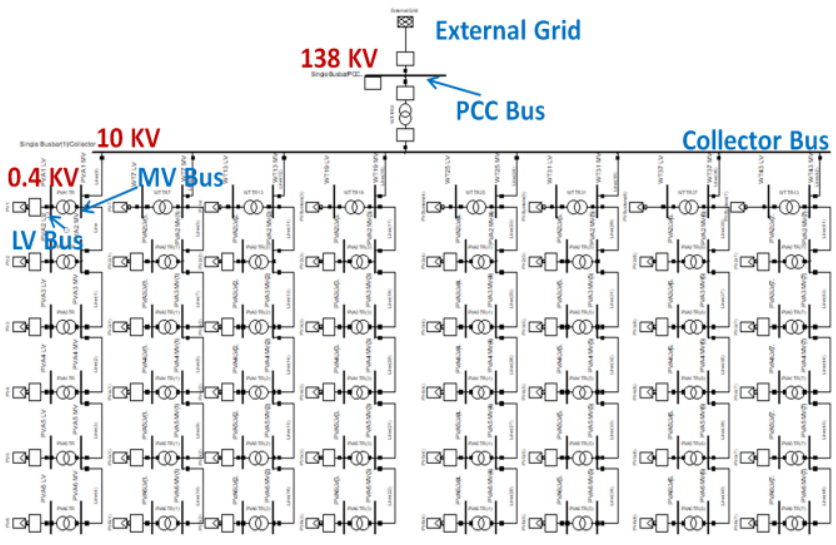

Fig. 4: PV plant

\section{Modelling of generators}

Doubly Fed Induction Generator (DFIG) is widely used in large wind plants hence it was used to model individual wind generators in the WF in this study. The individual wind generators [6] are set as 2.5 MVA units operating with power factor 0.8 and with wind turbine rotor diameter of $88 \mathrm{~m}$.

A typical PV system consists of solar array, controller and inverter. The relationship between PV cell, PV model (PV panel), PV string, and PV array is illustrated in Fig.5. Moreover, with respect to the location of inverters, three types of PV inverter are discussed: central inverter (Fig.6a), string inverter (Fig.6b) and module integrated inverter (Fig.6c) [8]. The central inverter topology connects parallel strings to a single inverter, thus keeping costs low whilst achieving high efficiency. It is widely used in medium and high voltage PV systems and is utilised in this study. For the string inverter, each string is combined with each inverter, decreasing mismatching and partial shading losses. For the module integrated inverter, each module has its own inverter, thus the energy yield is optimized [9].

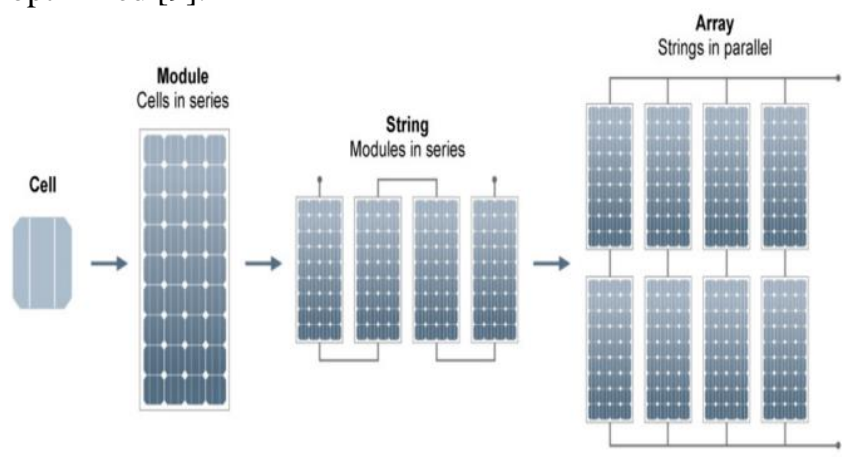

Fig. 5: PV components (adopted from [7])

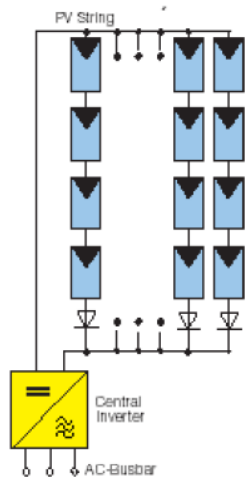

(a)

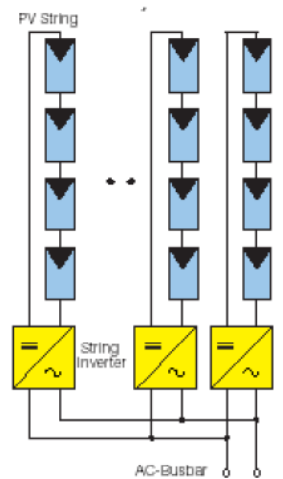

(b)

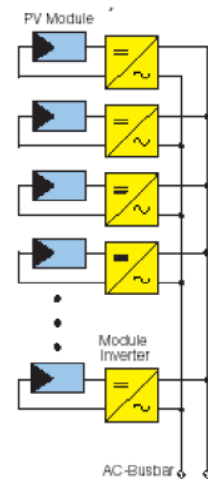

(c)
Fig. 6: (a) PV central inverter, (b) PV string inverter, (c) PV module integrated inverter (adopted from [9])

In this study, the PV power plant is divided into 48 substations of 1MVA each and each 1MVA substation consists of 4 array channels, each rated 500KVA with power factor 1. Each array channel is equipped with an inverter converting $\mathrm{DC}$ to $\mathrm{AC}$, which means 4 parallel inverters in each PV section. Both WF and PV plant are connected to $50 \mathrm{~Hz}$ power system.

\section{Modelling of probabilistic power input}

Weibull distribution (Fig.7) and Beta distribution (Fig.8) are continuous probability distributions that are commonly used to describe the wind speed variation and the solar irradiation variation during the year, respectively [10], hence they are used for modelling WF and PV plant power output in this study.

Based on Fig.7 and Fig.8, appropriate probability distributions of respective power outputs are generated in MATLAB and sampled randomly (500 random values) for each individual wind and PV generator. These 500 random values or individual generators are then transferred to DigSILENT so in each of 500 iterations each individual generator is modelled as an independent probabilistic power injection. 


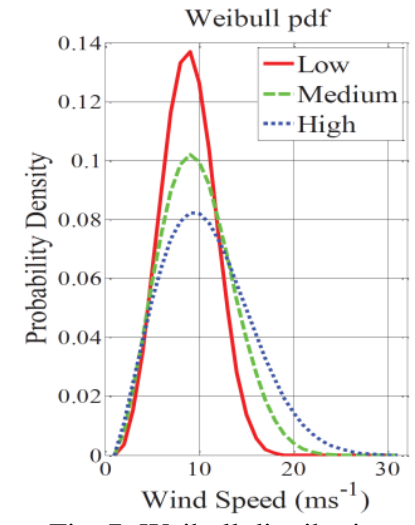

Fig. 7: Weibull distribution

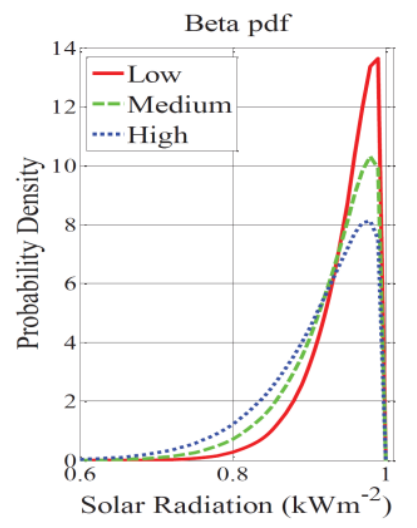

Fig. 8: Beta distribution

\section{Modelling of cables}

Generally, the transmission line and cables are modelled as $\pi$ equivalent circuit in DigSILENT. In most cases, WTs are connected through AC Cross-Linked Poly Ethylene (XLPE) 3-core submarine cables with a Copper or Aluminium conductor [4]. Cable parameters chosen for this study are adopted from the Lillgrund wind power plant technical datasheet [11]. With more generators connected in one string, the cross section of cable should be larger in order to withstand the accumulated current. In this project, the cross section of cables with respect to the numbers of wind generators in one string is shown as Fig.9. Generally, the separation distance between WTs is considered 5-8 times that of rotor diameters [4]. Therefore, the length of cables between WTs is chosen to be $0.5 \mathrm{~km}$ and the length of cables connected to collector bus is set as $1 \mathrm{~km}$.

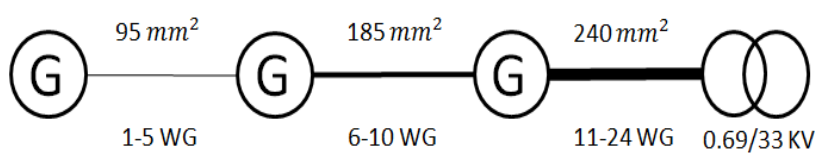

Fig. 9: Different cross-sections of cables in WF model

In PV plant modelling, the cables connecting each section are selected as NA2YSY $1 \times 500 \mathrm{rm} 6 / 10 \mathrm{kv}$ in DigSLIENT library [3]. The rated voltage is $10 \mathrm{KV}$, each cable being $0.02 \mathrm{~km}$ in length.

\section{Modelling of harmonic injections}

The harmonic current magnitude and angle injections by individual harmonic sources vary in real life depending on the source operating conditions. Hence, the range of harmonic injections is based on the results of long-term measurements of the harmonic spectrum and reported documents about the performance of PE interfaced devices.

The harmonic magnitudes and phase angles for characteristic harmonics used in the study are assumed to be within the ranges shown in Table 1. The Monte Carlo simulations considering different probability distribution of injected harmonics is carried out to represent the probabilistic operation of the network. The same harmonic injection is modelled in each of the three phases. In addition, since each PV section consists of 4 parallel inverters, the values of the harmonic injections are multiplied by 4 before being injected into to the system.
Table 1: Harmonic injection ranges [12]

\begin{tabular}{ccc}
\hline Harmonic order & Magnitude $(\%)$ & Phase (degree) \\
\hline 5 & $0-0.05$ & $0-180$ \\
7 & $0-0.1$ & $0-180$ \\
11 & $0-0.15$ & $0-180$ \\
13 & $0-0.2$ & $0-180$ \\
\hline
\end{tabular}

\section{Modelling of wake effect and shading effect}

The wake effect refers to the wake area where the wind speed decreases as the WT draws energy from the wind. It leads to an uneven distribution of wind speed in the WF, affects the operation status of each WT, and influences the operating conditions and output of the WF [13]. Since the wake effect depends on the WT location, it is possible to model it as a certain scaling factors (sf) with respect to WT separation (based on the Figure 3.7 in [4]). In this project, three wind directions are considered to illustrate the wake effect: blowing from left to right horizontally, downwards to upwards vertically and from lower left to upper right at $45^{\circ}$. The chosen scaling factors are shown in Fig. 10 for WF with parallel configuration. For star and $\mathrm{T}$ connection, the selection of wake effect scaling factors is roughly the same.

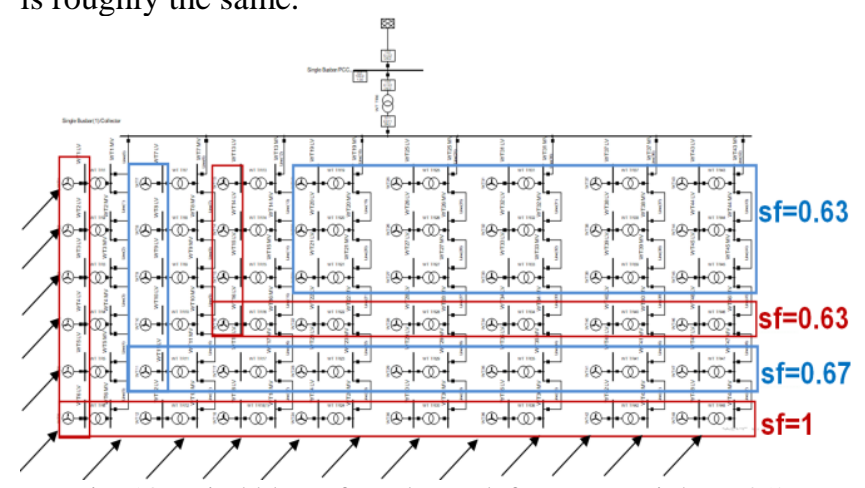

Fig. 10: Wind blows from lower left to upper right at $45^{\circ}$

The PV modules of Large-scale PV plants are easily shaded by clouds, leaves and other shields. Moreover, there will be surrounding buildings or utility poles covering the PV cells. The front and back rows of PV array might also block each other. The shaded PV module will then act as the load that dissipates the energy generated by other modules. As a result, the shaded PV cell will heat up, causing hot spot effect, decreasing the output performance or even shortening the service age. These phenomena are known as partial shading effects. The scaling factors of the partial shading effect depend on the shading percentage and can be calculated based on Fig.7 in [14]. In this study, two shading samples are considered: trapezoidal and rectangular shading. The chosen scaling factors are as shown in Fig.11.

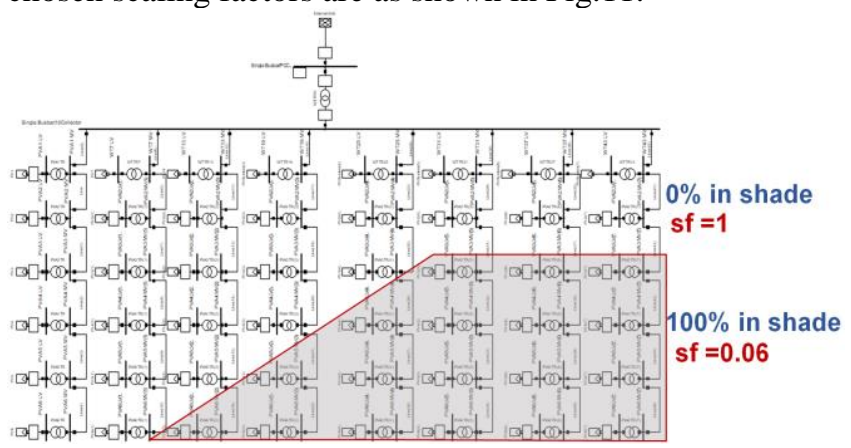

Fig. 11: Trapezoidal shading 


\section{CASE STUDY}

\section{Wind farm case studies}

For the assessment of WF harmonic contribution disconnections/ unavailability of individual WT, different operating points based on Weibull distribution, wake effect and different WF configurations are considered. The WF case studies are classified by configuration. For the parallel configuration, $\mathrm{CmC} 0$ refers to all WTs connected; $\mathrm{CmC} 1$ refers to one column of WTs disconnected; with additional columns of WTs disconnected, the cases are named as $\mathrm{CmC} 2-\mathrm{CmC} 8$, respectively. Similarly, RwC 0 refers to all WTs connected and with additional row of WTs disconnected, the cases are named as RwC 1- RwC 6. Furthermore, all the 48 WTs are divided as 6 groups of diagonal WTs. Similarly, with each group of diagonal WTs disconnected, the cases are named as DC 1- DC 7, respectively. WEC 13 refers to the wake effect considering three wind directions: blowing from left to right horizontally, downwards to upwards vertically and from lower left to upper right at $45^{\circ}$. They are simulated by considering different scaling factors as discussed above. In order to analyse the impact of different WF configurations, three additional case studies are considered with each of the three configurations. CoC 0 refers to all WTs connected; CoC 1 includes the wake effect when all WTs are connected, and CoC 2 considers WFs with 16 randomly disconnected WTs with the wake effect included. Note that the $\mathrm{CmC} 0$, RwC 0, DC 0, WEC 0 and $\mathrm{CoC} 0$ are the same. All power injections of WTs follow the Weibull distribution.

The absolute values of the THD and the individual harmonic distortions for the $5^{\text {th }}, 7^{\text {th }}, 11^{\text {th }}$ and $13^{\text {th }}$ harmonic are plotted in Fig. 12 and the normalised $95^{\text {th }}$ percentile values in Fig.13 for parallel configuration of WF. The worst case is the $\mathrm{CmC} 0$ with $95^{\text {th }}$ percentile THD of $0.01340 \%$.

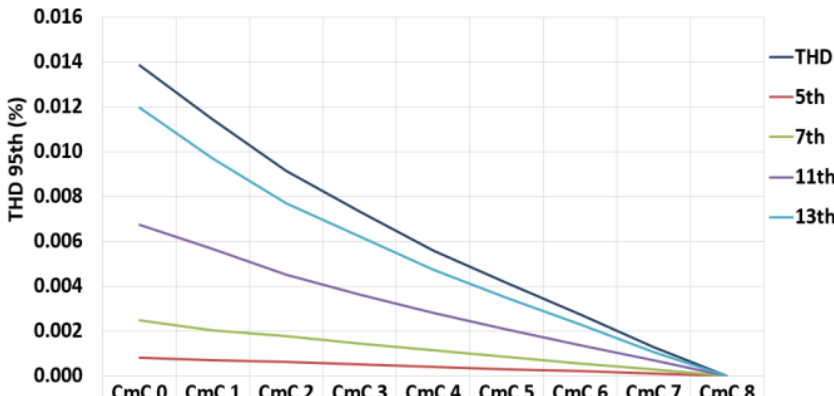

Fig. 12: THD and individual harmonic distortion values considering WF column cases (parallel)

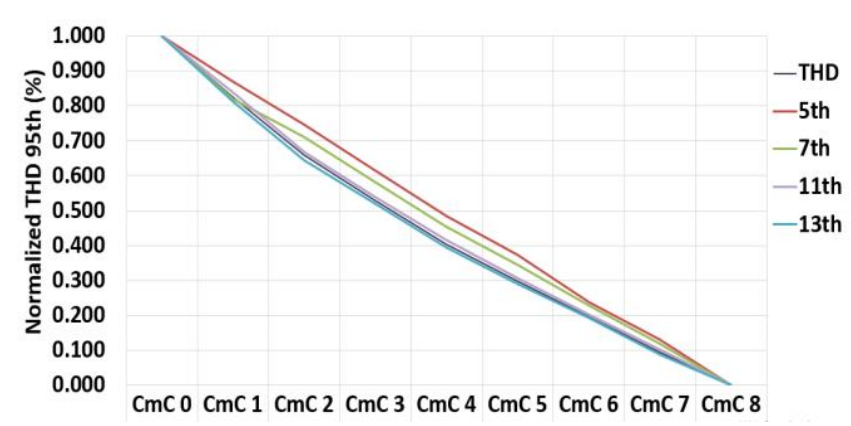

Fig. 13: Normalized THD and individual harmonic distortion values considering WF column cases (parallel)
As can be seen from the results, the $11^{\text {th }}$ and $13^{\text {th }}$ harmonics contribute the most to the overall THD at the point of connection of the WF. Furthermore, the THD reduces with disconnection of WTs, i.e., it is the largest with all WTs in service and the smallest with only one column of WTs working.

To compare the harmonic distortion of all simulated cases, including WT disconnections and wake effect, the normalized $95^{\text {th }}$ percentile THD values are compared in Fig.14. When the wake effect is considered, the $95^{\text {th }}$ percentile THD of all three cases decreases by around $30 \%$, regardless of the wind direction. Therefore, the aggregate WF harmonic injection can be determined by using scaling factor of 0.7 to account for the wake effect.

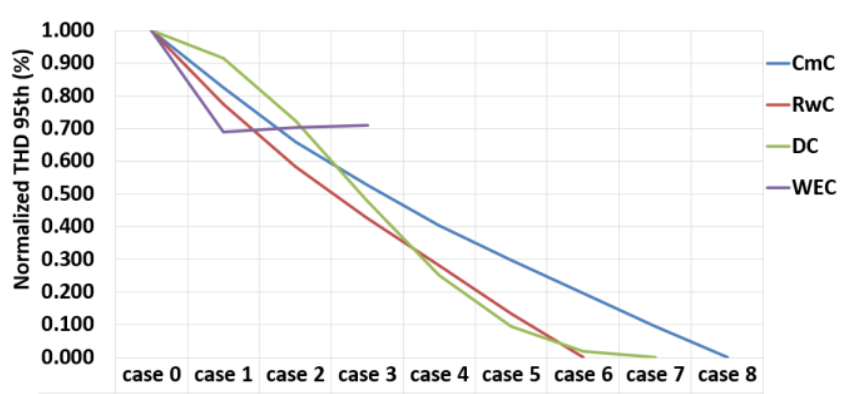

Fig. 14: Normalized WF THD combined cases (parallel)

In order to analyse the impact of different WF configurations, a specific wind direction is chosen. Taking the $\mathrm{T}$ configuration as an example, Fig.15 shows the original THD values with respect to $\mathrm{CoC} 0-2$. Similarly, as with parallel configuration when modelling the WF as $\mathrm{T}$ and star configurations, $5^{\text {th }}$ and $7^{\text {th }}$ harmonics injections are lower compared to $11^{\text {th }}$ and $13^{\text {th }}$. In terms of THD values, three configurations are compared in Fig.16.

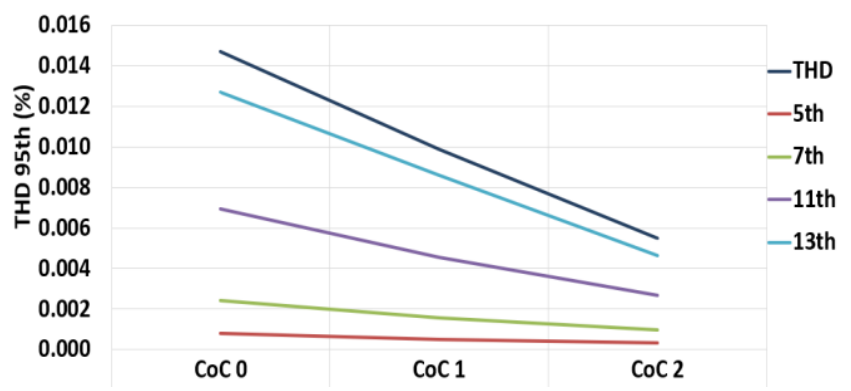

Fig. 15: THD and individual harmonic distortion values for WF $\mathrm{T}$ configuration

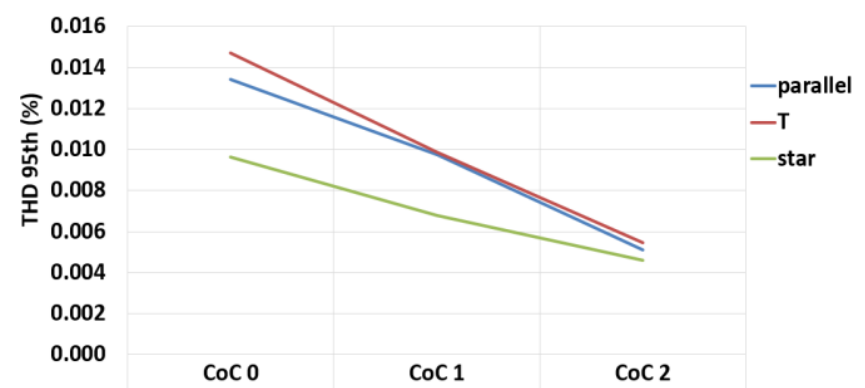

Fig. 16: $95^{\text {th }}$ percentile values of THD for parallel, T and star configurations

The star configuration resulted in the lowest THD comped with the other two. It should be noted though that the star configuration can be more expensive due to the extra 
length of cables and switchgears, therefore there is a trade-off between capital investment in WF design and potential cost of power quality mitigation. Considering the overall effect on the transmission system as a whole in terms of THD at the point of WF connection, the difference among the three configurations is negligible. Hence, it is possible to use the same equivalent harmonic model of WF regardless of the configuration. In addition, as mentioned above, the wake effect reduces THD value by approximately $30 \%$, hence it can be modelled as a scaling factor of 0.7 , irrespectively of the configurations and wind direction.

In order to verify the possibility of modelling the whole WF as a single harmonic source, only one WT is simulated considering 500 different harmonic injections based on Monte Carlo simulations as before. The results are then multiplied by 48 and compared with the results obtained with all 48 WTs connected including parallel, star and $\mathrm{T}$ configurations and excluding wake effect. Normal distribution is fitted (see Fig. 17) to calculated THD values to facilitate comparison of the mean values $(\mu)$ and standard deviations $(\sigma)$ for three different configurations. Compared with the results obtained using single WT multiplied by 48 , the mean value is $15.9 \%$ higher for parallel configuration, $16.7 \%$ lower for star configuration and $23.8 \%$ higher for $\mathrm{T}$ configuration, i.e., there is substantial variation in results. Therefore, if the WF is to be modelled as a single probabilistic harmonic generator, a scaling factor should be added for different WF configurations, which is 1.16 $(0.0073 / 0.0063=1.159)$ for parallel configuration, 0.86 $(0.0054 / 0.0025=0.857)$ for star configuration and 1.32 $(0.0083 / 0.0063=1.317)$ for $\mathrm{T}$ configuration .

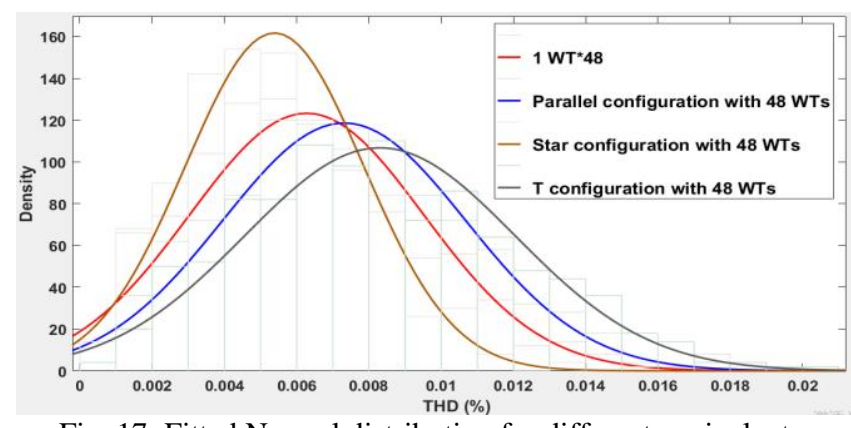

Fig. 17: Fitted Normal distribution for different equivalent modelling of WF

\section{PV Plant Case Studies}

Same as with WF parallel configuration cases, the simulated PV network disconnections are considered in each column, row and diagonal. In addition, the SEC 1-2 is considered with trapezoidal shading and rectangular shading, respectively. All harmonics injections of PV generators follow the Beta distribution. It has been found that the worst case is SEC 0 (same as with WFs) with the value of the $95^{\text {th }}$ percentile of THD of $0.17312 \%$. Fig. 18 shows the PDF values for THD and individual harmonics for the worst case, i.e., all PV inverters connected. With harmonic order increasing, the average value of THD rises, and the distribution becomes wider. Fig.19 presents the normalized THD, $5^{\text {th }}, 7^{\text {th }}, 11^{\text {th }}$ and $13^{\text {th }}$ harmonic values of diagonal cases. It can be seen that they fully overlap.

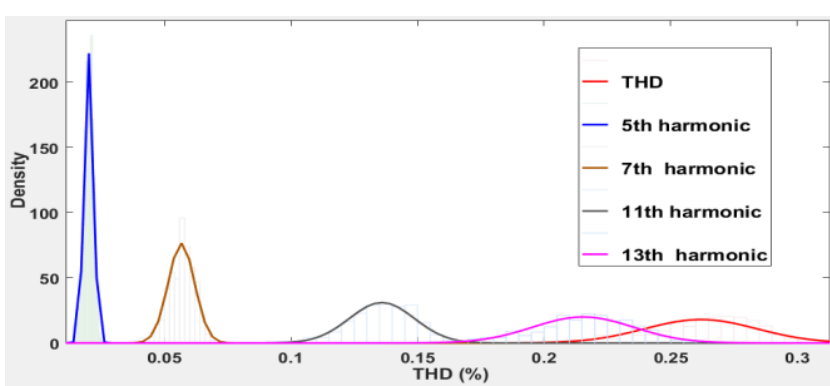

Fig. 18: PDF of PV worst case

Fig.20 presents the normalized values of the $95^{\text {th }}$ percentile of THD for CmC 0-8, RwC 0-6, DC 0-7 and SEC 0-2. As in the case of a WF, it appears that a PV plant mostly injects $11^{\text {th }}$ and $13^{\text {th }}$ harmonic. However, when considering the partial shading effect, it cannot be regarded as an equivalent scaling factor like the wake effect because it depends on the radiation percentage of the PV system. The more PV panels in shade, the less THD there will be and thus unable to maintain a stable constant.

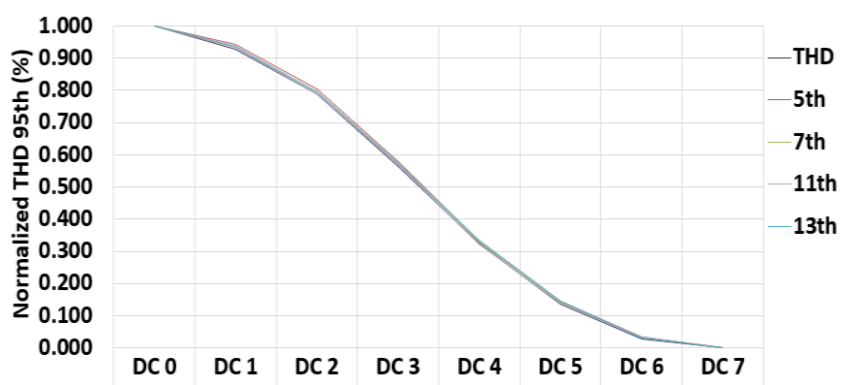

Fig. 19: Normalized THD and individual harmonic distortion values for PV diagonal cases

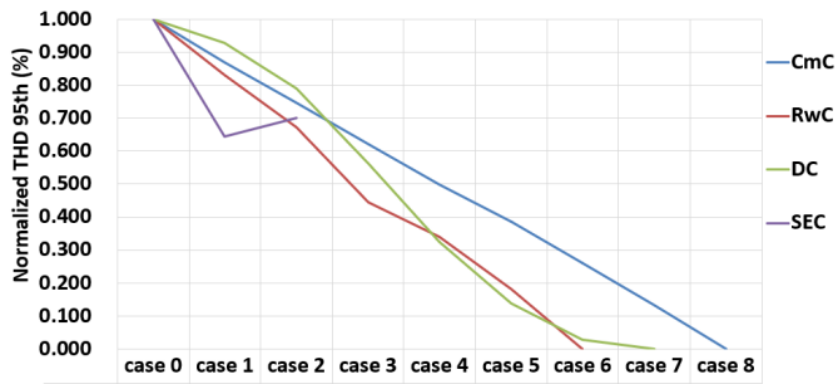

Fig. 20: Normalized PV plant THD combined cases

In order to verify the possibility of modelling the whole PV plant as a single harmonic source, only one PV generator is simulated as before considering 500 random harmonic injections and without partial shading effect. The results are multiplied by 48 and compared with the results obtained with all 48 PV generators connected. Fitted normal distribution of resulting THD is shown in Fig.21. The mean value of PDF when all $48 \mathrm{PV}$ generators are connected is smaller about $12.2 \%$ than when the plant is modelled as a multiple of single PV generator injections and the standard deviation is pretty large. Therefore, the PV plant should not be modelled as a multiple of injections by single generator as the results will be pessimistic (about 10\% higher THD values) and potential THD values widely spread. However, as a first approximation for exploratory studies not requiring very high accuracy the PV plant can be modelled as a single harmonic source, and a scaling factor of 0.88 $(0.15590 / 0.17749=0.878)$ should be considered in case of 
parallel configuration. The scaling factors for other PV plant configurations can be calculated in a similar way.

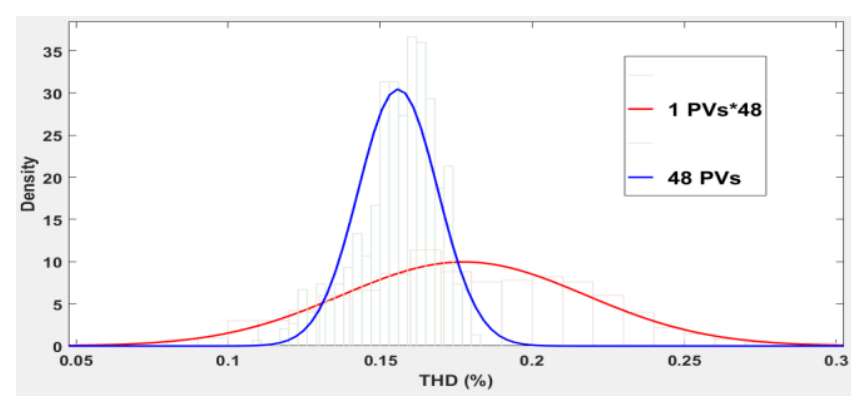

Fig. 21: Fitted Normal distribution for different equivalent modelling of PV plant

\section{Effect of cancellation on harmonic propagation}

To illustrate the effect of harmonic cancellation within a plant both WF (parallel) and PV plants are simulated with random values of magnitude of injected harmonics but with fixed phase angle 0 degrees. The results obtained at PCC bus are shown in Table 2.

Table 2: $95^{\text {th }}$ percentile of THD with different phase angle injected harmonics

\begin{tabular}{ccc}
\multicolumn{3}{c}{ injected harmonics } \\
\hline THD (\%) & Phase angle $0^{\circ}$ & Phase angle $\left(0^{\circ}-180^{\circ}\right)$ \\
\hline WF & 0.0148 & 0.0130 \\
PV & 0.1971 & 0.1743 \\
\hline
\end{tabular}

Compared with the results obtained when the phase angle of injected harmonics varied randomly between 0-180 degrees, the effect of cancellation is notable. For WF and PV plant, the cancellation will decrease the $95^{\text {th }}$ percentile value of THD at the PCC bus by approximate $13.8 \%$ and $13.1 \%$ respectively. Therefore, if the WF and PV plant are to be modelled as a single harmonic source with fixed phase angle the effect of cancellation can be modelled by introducing the same scaling factor of 0.88 $(0.0130 / 0.0148=0.88$ for WF, $0.1743 / 0.1971=0.88$ for PV $)$.

\section{CONCLUSION}

The paper presented exploratory study to inform equivalent harmonic modelling of wind and PV plants for large transmission system harmonic propagation studies. Different plant configurations, individual generator availability, shading and wake effects and harmonic cancellation are considered. It is shown that both RES can be modelled in a first approximation as a single probabilistic harmonic generator with appropriate scaling factors, summarised in Table 3, to account for harmonic cancellation, different plant configurations and different weather conditions. These equivalent models could be used in large transmission system harmonic propagation studies with a great efficiency and confidence to identify potential harmonic issues in the network. If those are identified then more detailed modelling of individual plant is required for harmonic mitigation, however, in this case the extent of network modelling can be substantially reduced.

Table 3: Scaling factors

\begin{tabular}{ccccccc}
\hline & WF & WF & WF & WF & PV & \multirow{2}{*}{ Cancellation } \\
& Parallel & Star & T & Wake Effect & Parallel & \\
\hline SF & 1.16 & 0.86 & 1.32 & 0.70 & 0.88 & 0.88 \\
\hline
\end{tabular}

\section{ACKNOWLEDGMENT}

This research was partly supported by the EU Horizon 2020 project "MIGRATE”, contract number 691800.

This paper reflects only the author's views and neither the Agency nor the Commission are responsible for any use that may be made of the information contained therein.

\section{REFERENCES}

[1] T. C. Sekar and B. J. Rabi, "A review and study of harmonic mitigation techniques," in Emerging Trends in Electrical Engineering and Energy Management (ICETEEEM), 2012 International Conference on, 2012, pp. 93-97: IEEE.

[2] S. Abdelrahman, "Estimation and provision of differentiated quality of supply in distribution networks," University of Manchester, 2016.

[3] D. PowerFactory, "PowerFactory User's Manual," DIgSILENT, GmbH, vol. 14, 2011.

[4] M. Ali, "Probabilistic Modelling Techniques and a Robust Design Methodology for Offshore Wind Farms," University of Manchester, 2012.

[5] G. Quinonez-Varela, G. Ault, O. Anaya-Lara, and J. McDonald, "Electrical collector system options for large offshore wind farms," IET Renewable Power Generation, vol. 1, no. 2, pp. 107-114, 2007.

[6] 'Technical documentation wind turbine generator systems GE 2.5/88, $\quad$ http://www.generalequipment.info /2\%205_88_TD_allComp_xxxxxxxx\%20ENxx\%2001.pdf, accessed 24 February 2018.

[7] 'Photovoltaic systems', http://www.yourhome.gov.au/ sites/prod.yourhome.gov.au/files/pdf/YOURHOME-

Energy-PhotovoltaicSystems.pdf, accessed 24 February 2018.

[8] F. Mahmood, "Improving the Photovoltaic Modelin PowerFactory," ed, 2012.

[9] F. Blaabjerg, R. Teodorescu, Z. Chen, and M. Liserre, "Power converters and control of renewable energy systems," in Proc. 6th Int. Conf. Power Electron, 2004, vol. 1 , pp. 1-20.

[10] K. Hasan, R. Preece, and J. Milanović, "Efficient identification of critical parameters affecting the smalldisturbance stability of power systems with variable uncertainty," in Power and Energy Society General Meeting (PESGM), 2016, 2016, pp. 1-5: IEEE.

[11] E. Eriksson, "Wind farm layout: a reliability and investment analysis," ed, 2008.

[12] E. Bećirović, J. V. Milanović, S. Hellmuth, M. Kuschke, K. Strunz, and D. Matvoz, "Propagation of PQ disturbances through the power networks," 2018.

[13] F. González-Longatt, P. Wall, and V. Terzija, "Wake effect in wind farm performance: Steady-state and dynamic behavior," Renewable Energy, vol. 39, no. 1, pp. 329-338, 2012.

[14] C. Deline, "Partially shaded operation of a grid-tied PV system," in Photovoltaic Specialists Conference (PVSC), 2009 34th IEEE, 2009, pp. 001268-001273: IEEE. 